\title{
DESIGNER FLUID PERFORMANCE AND INCLINATION ANGLE EFFECTS IN A FLAT GROOVED HEAT PIPE
}

\author{
Jacob Supowit, Thomas Heflinger, Michael Stubblebine, Ivan Catton, \\ University of California, Los Angeles, 420 Westwood Plaza, Los Angeles, CA 90095-1597 \\ Mechanical and Aerospace Engineering Department \\ Morrin-Martinelli-Gier Memorial Heat Transfer Laboratory \\ e-mail: jake.supowit@gmail.com
}

\begin{abstract}
A flat heat pipe was used to study the effects of an advanced working fluid previously shown to improve the thermal performance of phase change heat transfer devices through surface augmentation of the wick. Surface structures were created by the working fluid through chemical oxidation reactions and solubility forced deposits. The modular heat pipe apparatus allowed water and the advanced working fluid to be compared in the same device. A clear viewing cover plate allowed for visual observation of the evaporating section of the heat pipe. The setup was first tested for repeatability with water and produced three sets of thermal resistance values within 5\%. The advanced working fluid decreased the thermal resistance by approximately $20 \%$ and nearly tripled the capillary limit. The advanced working fluid was also tested at larger angles and was able to maintain normal operation due to the additional capillarity of the fluid deposits. This work also provides insight into the design of fluids for other wick geometries by examining the effect of increasing the concentration of the fluid and how the fluid deposits on the surface. The results indicate that concentration of the fluid was over the amount necessary for the evaporative surface area of the grooved wick.
\end{abstract}

Keywords: Flat heat pipe, Phase change heat transfer, advanced working fluid, Inorganic aqueous solution (IAS), grooved wick

\section{INTRODUCTION}

Thermal management challenges in electronic devices and systems have emanated from progressive increases in power consumption and decreases in component size. Heat produced by even consumer devices has soared past expected cooling needs requiring more advanced thermal technologies. Heat pipes and other phase change heat transfer devices have been a popular method of transferring heat for decades due to their passive and efficient nature [1].

High heat flux cooling needs has led to a variety of research devoted to development of novel heat pipe wick structures and designer fluids [2-4]. Typically a working fluid is chosen based on its dimensionless Merit number and operating temperature range limiting the possibility for performance improvement in this aspect of heat pipe design. However, several types of advanced working fluids, such as binary fluids, nanofluids, and other designer fluids offer additional mechanisms for thermal performance enhancement. The purpose of a designer fluid is to either alter the properties of the fluid or the evaporating surface. For example, binary fluids can adjust operating temperature ranges and surface tension gradients while nanoparticle suspensions, known as nanofluids, leave a coating of nanoparticles on the surface of the wick while increasing the thermal conductivity of the solution. This deposited coating has been shown to increase evaporative performance in phase change heat transfer devices through the extra capillarity and wetting ability of the small coating pores [5-8].

A unique group of designer fluids has been developed from the originally patented Inorganic Aqueous Solution (IAS) created and studied at UCLA [9, 10]. These fluids create microstructures on the surface of the wick in situ through chemical reactions and solubility forced deposits. This surface augmentation is inherently hydrophilic and has shown to increase the performance and dry-out heat flux in a variety of wicks. To the author's knowledge, these fluids have been the first attempt at using dilute aqueous solutions for performance enhancement in phase change heat transfer devices. This type of chemically reacting working fluid is particularly promising because of the cost, and reliability associated with the inorganic constituents and coating respectively.

The chemical composition and basic transport mechanisms of the generated coating have been identified in previous research studies and are summarized below. However, several design aspects are still unaddressed and require investigation. Before the fluid constituents and concentration can be optimized, the deposition mechanisms must be examined. The goal of this work was to further develop the designer fluid design process by examining how the coating is deposited in a wick through its performance in a grooved flat heat pipe. Changes in thermal resistance and the heat transport limit as well as the nature of the fluid deposits will provide insight into further development of the advanced working fluid. A modular flat heat pipe was designed and fabricated to allow visual observation during operation and dry-out of the wick. 


\section{BACKGROUND OF IAS DESIGNER FLUIDS}

\subsection{Chemistry}

A detailed analysis of the chemical processes that occur when the IAS-based fluids are used in heat pipes was done by Yao et al. [11]. The analysis demonstrates the temperature and concentration dependence of the coating generation as well as the key chemical constituents. Supowit et al. [12] confirmed some of this analysis through surface characterization and elemental composition analysis with fluids of different concentrations at different temperatures.

The original IAS fluid patented at UCLA [9] was used as a baseline guide for the concentration of each fluid. The original fluid, will be referred to as IAS 1.1. The first number refers to the ratios of constituents concentrations, and the number after the decimal designates the overall molar concentration multiple of the original fluid. For example, IAS 2.2 has different mix ratios than IAS 1.1 but twice the concentration as IAS 2.1. The class of fluids used in this study, IAS 2.1 and 2.2, differ by exclusion of $\mathrm{Ag}_{2} \mathrm{CrO}_{4}$. The silver ions, though they may be important for aluminium passivation, are useless for performance enhancement in copper devices, especially at such low concentrations [11].

Table 1: IAS fluid constituent concentrations

\begin{tabular}{|c|c|c|}
\hline \multicolumn{3}{|c|}{ Designer Fluid } \\
Compound Mass (g/L) \\
\hline Chemical & $\# 2.1$ & $\# 2.2$ \\
\hline $\mathrm{KMnO}_{4}$ & 0.442 & 0.8833 \\
\hline $\mathrm{K}_{2} \mathrm{Cr}_{2} \mathrm{O}_{7}$ & 8.5385 & 17.0888 \\
\hline $\mathrm{CrO}_{3}$ & 1.9163 & 3.8374 \\
\hline $\mathrm{Sr}(\mathrm{OH})_{2}$ & 0.1062 & 0.2103 \\
\hline $\mathrm{Ca}(\mathrm{OH})_{2}$ & 0.9801 & 1.9519 \\
\hline $\mathrm{Mg}(\mathrm{OH})_{2}$ & 0.0367 & 0.0679 \\
\hline $\mathrm{NaOH}$ & 0.5545 & 1.1159 \\
\hline $\mathrm{pH}$ & 6.18 & 6.37 \\
\hline
\end{tabular}

Two different concentrations of IAS 2 were studied in this work, shown in Table 1, with the goal of examining the effect of overall concentration on the deposits in a specific wick structure. The enhancement mechanisms of the fluids have been identified in the past, but the magnitude of concentration was fairly arbitrary. Different concentrations allowed for observation on any additional deposits or performance enhancements that occurred.

\subsection{Performance Enhancement}

Various studies have exemplified the thermal improvement potential of the IAS designer fluids through surface wetting and capillarity of the surface augmentation. By examining the thawing process of droplets, Supowit et al. [13] demonstrated that the surface features created by the IAS fluid wicked liquid water from underneath the frozen droplet as it thawed. The spreading phenomenon is a result of hemi-wicking, a concept developed by Bico et al. [14]. For some surface structures and roughness, liquid may imbibe into the surface features due to a capillary effect similar to that seen in typical porous media and described by Washburn's Law. For a heat pipe, the coating can act as additional wick with smaller pores providing additional capillarity.

The small pore size also utilizes thin film evaporation to increase the evaporative heat transfer coefficient. More evaporative surface area is covered by the highly efficient interline region studied by Wayner et al. [15]. This is the concept behind fabricated micro- and nano-structured wicks.

Reilly and Catton [10] tested the original fluid in bi-porous sintered wick slugs in a vapor chamber and found large decreases in the temperature difference after the dry-out point of the large pores. The exposed coating on the outer surface of the clusters kept the surface wetted, increasing the evaporative surface area. However, the performance degraded over time. This degradation was attributed to clogging of the wick pores due to the excessive amount of reservoir fluid in the chamber. A properly designed device would not have an essentially unlimited amount of charge. The mass of coating producing chemicals would be orders of magnitudes less than provided by the vapour chamber reservoir. These results demonstrate the importance of determining the proper fluid concentrations and deposition mechanisms and provide motivation for the work in this study.

\section{EXPERIMENTAL SETUP AND PROCEDURE}

A flat heat pipe (FHP) or vapor chamber was used to test the thermal performance of the designer fluids and examine the nature and location of the deposits.

The goal of the modular design was to allow consistent testing of various working fluids and wick structures. Similar designs have been successfully utilized to study grooved and sintered wicks by Wong and Chen [16] and Stubblebine and Catton [17].

\subsection{Flat Heat Pipe Apparatus}

The heat pipe test setup consisted of a vapor chamber with an internal volume measuring $3 \mathrm{~cm} \times 13 \mathrm{~cm} \times 1 \mathrm{~cm}$. The top piece was a clear acrylic viewing window to observe liquid wetting, fluid deposits, and dry-out of the grooves. The stainless steel frame was sealed to the top window and grooved copper plate with Viton fluoroelastomer O-rings of durometer A90. A schematic of the chamber cross section is shown in Figure 1.

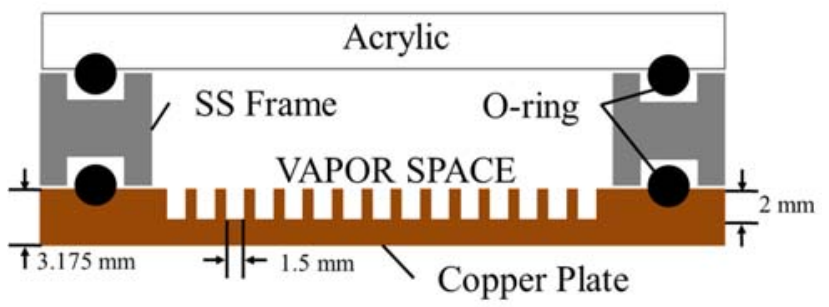

Figure 1: Flat heat pipe vapor chamber schematic

15 rectangular grooves measuring $1.5 \mathrm{~mm}$ wide by $2 \mathrm{~mm}$ were milled in a $3.175 \mathrm{~mm}$ thick plate. This groove size, while relatively large, was chosen for machinability, low cost, and dry-out visualization. Ten calibrated Type-T thermocouples were attached to the back side of the plate with thermal adhesive as shown in Figure 2. 


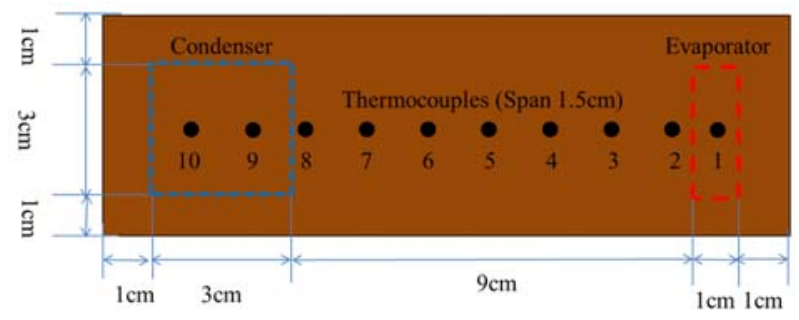

Figure 2: Thermocouple map

A schematic of the FHP apparatus is shown in Figure 3. The copper heater block was embedded with two $200 \mathrm{~W}$ cartridge heaters. The plate was soldered to a copper heating stem and cooling block to ensure good thermal interfacing and consistency between experiments. The stem had a $3 \mathrm{~cm} \times 1 \mathrm{~cm}$ cross section and was $3 \mathrm{~cm}$ long to allow the input power to be measured via Fourier's Law. Thermocouples were spaced at 3 $\mathrm{cm}$ along the stem with the top thermocouple adjacent to the plate. The cooling block was $3 \mathrm{~cm} \times 3 \mathrm{~cm}$ and cooled by ice water pumped by a peristaltic pump at $3.47 \mathrm{~mL} / \mathrm{s}$. The low flowrate allowed the inlet and outlet temperatures to differ enough to perform calorimetry. Another thermocouple was soldered into the steel frame to measure the vapor temperature.

The stainless steel frame was clamped between the viewing window, a top wooden pressure piece, and the grooved copper plate as shown in Figure 3. The wood piece assisted in spreading the force of the clamps to help uniformly distribute pressure along the O-rings. In order to prevent condensation on the viewing window, a heater block and temperature controller were used as a guard heater to keep the window temperature and vapor temperature equal.

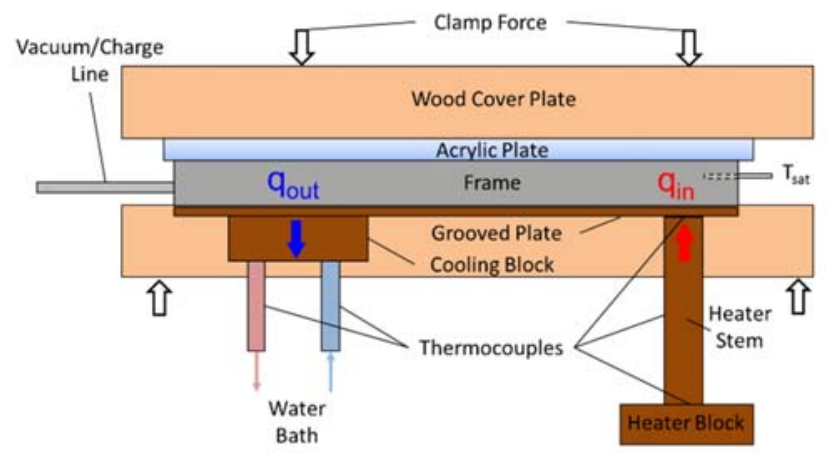

Figure 3: Schematic of flat heat pipe apparatus

The actual test setup is shown in Figure 4. A high accuracy Agilent 34401A 6 $1 \frac{1}{2}$ digit multimeter was used to measure the voltage from the thermocouples with the assistance of an Omega thermocouple selector switch.

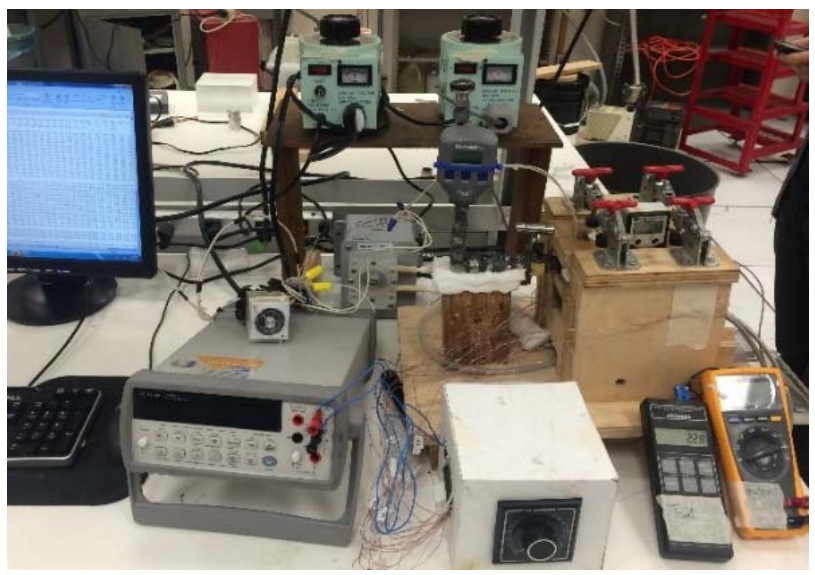

Figure 4: Physical Test setup

\subsection{Test Procedure}

The grooved copper plate was first cleaned with methanol to remove any oil or vacuum grease that might have contaminated the sample during handling. The plate was then washed with a $6 \mathrm{M}$ solution of nitric acid to remove any oxides and generate a clean copper surface. The surface was rinsed thoroughly with de-ionized water and air dried. Dow Corning vacuum grease was applied to the O-ring and the steel block was clamped between the acrylic viewing plate and the copper grooves.

The FHP was vacuumed through a charging station by an Agilent DS 302 vacuum pump for two hours so that the materials could properly out-gas and all remaining liquid has been evaporated due to the low pressure. The seal in the FHP was tested by measuring the leak rate of the system before charging. The Omega pressure transducer in the charging station had a range of 0-5 PSI over $100 \mathrm{mV}$ so that small leaks could be detected. The Agilent multimeter was used for precise microvolt readings. If the pressure reading did not change in 15 minutes the chamber was charged. A charge of $7 \mathrm{~mL}$ was used for all fluids. The volume of the grooves was $5.85 \mathrm{~mL}$ which corresponds to a $20 \%$ excess charge. Once the flat heat pipe was charged, the setup was inclined to the proper angle using a digital angle gauge.

This charge volume was chosen to avoid premature dry-out do to condensation on the side walls of the stainless steel frame. The $1 \mathrm{~cm}$ frame height and the lack of wick on the walls caused a significant amount of fluid to be retained as condensed vapor droplets, preventing some fluid from reentering circulation. The excess fluid was introduced to prevent this from causing early dry-out. It could be argued, the addition of charge volume slightly extended dry-out, but considering the small excess and the amount estimated to be withheld on the frame, the effect would be negligible.

Once the heat pipe was inclined the excess fluid spread out over the condenser. Even with a thickness on the order of a millimeter, the resulting film added an additional thermal resistance in the condenser. It was assumed this resistance was constant for each angle of inclination.

A variac was used to adjust the heater to various heat fluxes based on the electrical resistance of the heater and measured voltage. The actual heat input was calculated from the temperature measurements on the heater stem. The heat input was kept constant until the flat heat pipe reached steady state. The heat pipe was considered to be steady if none of the temperatures changed by more than one degree Celsius in 15 minutes. During the test, the heater block on the viewing 
window kept at the measured saturation temperature to prevent condensation. The input power was incremented until dry-out of the evaporation region occurred. This performance failure was determined by several criteria. A Scienscope microscope camera was used to view the grooves through the acrylic cover plate to determine dry-out. This condition also caused a sharp increase in the temperature difference between thermocouples on the plate. Thermal resistance was calculated from the input power and the temperature difference between thermocouple $\# 1$ and the average of thermocouple \#9 and \#10 as seen in Figure 2. Dry-out of the wick was also identified by the presence of an inflection point in the thermal resistance of the heat pipe $(R=\Delta T / q)$.

\section{EXPERIMENTAL RESULTS}

\subsection{Preliminary Tests and Repeatability}

The first several experiments used water as the working fluid in order to obtain baseline data to compare to the performance of the designer fluids, as well as check for repeatability. The preparation and procedure detailed above was followed for each water test. An inclination angle of three degrees was chosen after some preliminary testing. The low capillarity of the large grooves required a low angle to be initially fully wetted. For groove sizes of this magnitude the majority of the liquid pressure drop along the groove is due to gravitational head, instead of fractional losses. This made the heat pipe very sensitive to angle. At a six degree inclination, for example, the liquid receded in the grooves without any application of heat. Three degrees was used as baseline instead of a zero inclination due to the large permeability of the grooves. Without any gravitational head, the grooves would have an enormous maximum capillary limit at the axial length scale of this heat pipe.

An example of an axial temperature profile for third water run is shown in Figure 5.

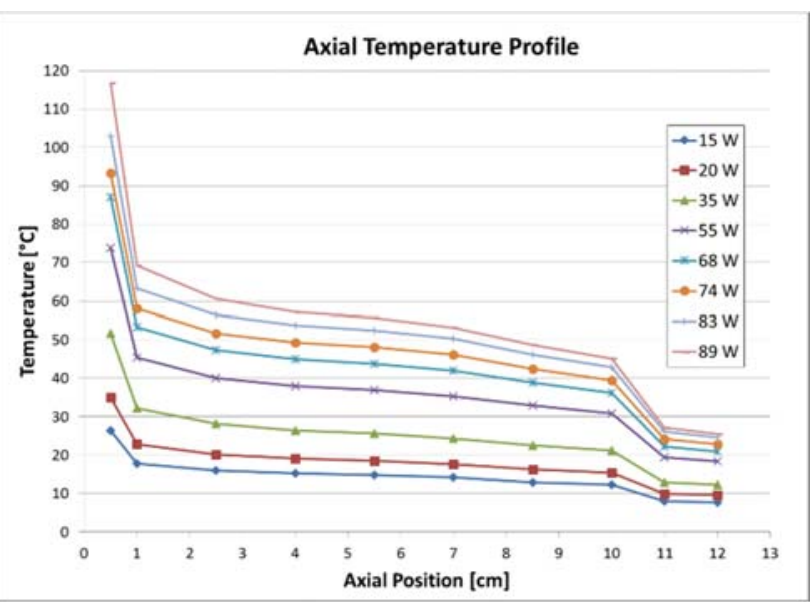

Figure 5: Axial temperature profile versus for different input powers

At low input powers, the temperatures along the adiabatic region of the heat pipe are fairly uniform as expected. A slight slope was expected due the relatively thick, high conductivity wick that would allow some axial conduction. At the power increases, the slope of the adiabatic region increases, especially near the evaporator region. This was a sign of dry out and transfer of heat through axial conduction.
The thermal resistance values and temperature differences for all three runs are shown in Figure 6 and Figure 7. A third order trend line was used to plot the data in Figure 6. The resistance value at each point along the lines were all within five percent of the values for the other runs demonstrating excellent repeatability. The values in Figure 7 for temperature difference appear even closer.

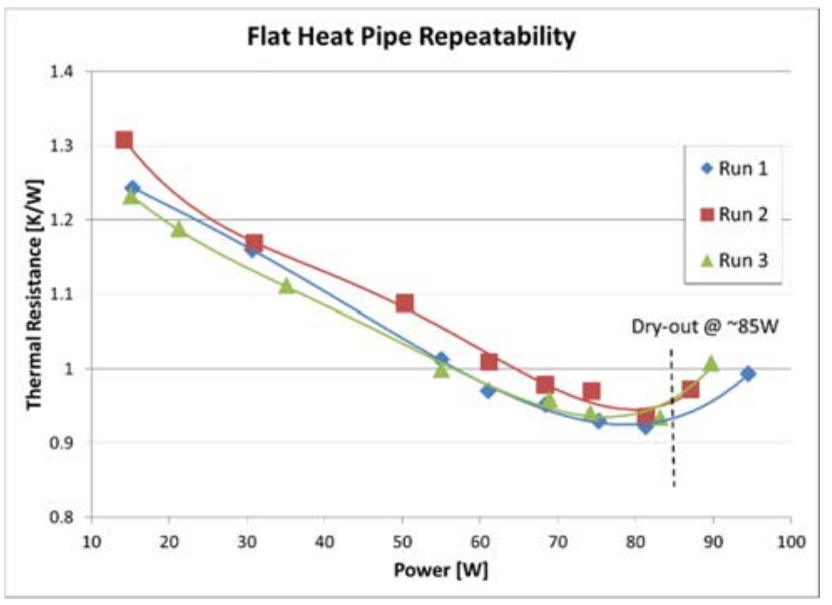

Figure 6: Flat heat pipe repeatability

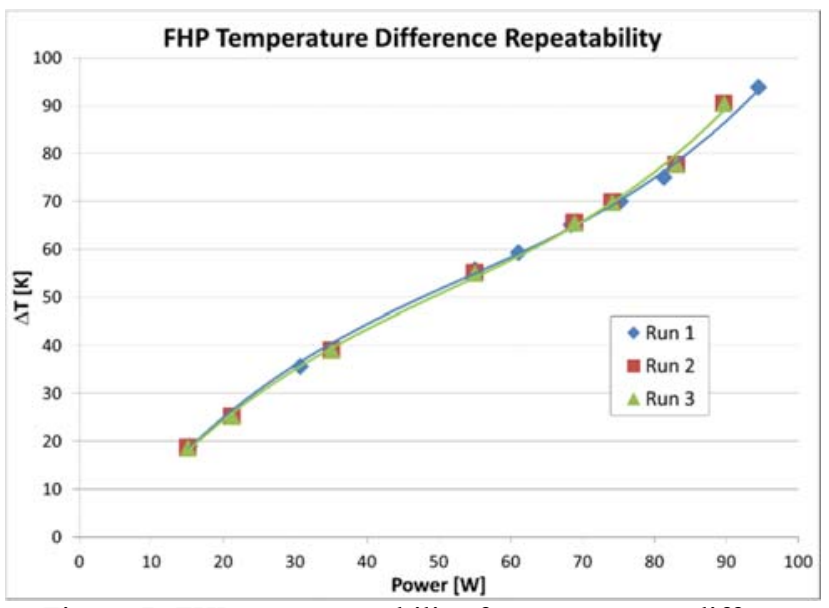

Figure 7: FHP test repeatability for temperature difference measurement

The resistance values are more scattered because the plotted values were calculated based on more measured data points than the temperature difference alone. The resistance measurement accrues the inherent uncertainty in the temperature difference measurement as well as the uncertainty in the input power measurement, systematically increasing the inherent total uncertainty. Even so, the flat heat pipe testing procedure was considered repeatable. A more detailed uncertainty analysis is described in Section 4.4.

As each test progressed the thermal resistance decreased steadily until approximately $85 \mathrm{~W}$. The resistance values at powers at and above $85 \mathrm{~W}$ increased sharply and generally did not reach steady state as rapidly as at lower powers. This inflection point in the resistance measurements was identified as the point of dry-out. The evaporator section at the top of the grooves was also physically observed through the acrylic cover plate to be dry at these powers. 
Though the inflection point occurred near $85 \mathrm{~W}$, nucleation was observed in the range $60-80 \mathrm{~W}$. Bubbles in the grooves expanded to the liquid-vapor interface intermittently. Below 80 $\mathrm{W}$, the nucleation did not cause dry-out. Liquid was pushed from the groove but was able to re-wet the surface. However, the nucleation frequency became large enough to eventually dry-out the grooves. Nucleation is typically considered a cause of dry-out in a variety of wicks and referred to as the boiling limit [18]. However, several studies have shown that nucleation in grooved wicks does not constitute an operation limit and may even increase the performance of the heat pipe $[19,20]$. Chen et al. [21] studied capillary and boiling limits in 200-500 $\mu \mathrm{m}$ square cooper grooves. A small $1 \mathrm{~cm}^{2}$ heater area was utilized to create nucleation occurred at very low heat fluxes but did not cause dry-out. In the current work, differences in heater area, tilt angle, and groove size, and wettability of the wick surface may have contributed to dry-out from nucleation.

\subsection{Designer Fluid Performance}

To investigate the effect of the designer fluid IAS 2.1 on performance of the FHP, the fluid was tested at the inclination angles of three, five, six, and seven degrees and the results are shown in Figure 8. For direct comparison, IAS 2.1 was first tested at an inclination angle of three degrees to compare thermal resistance and the point of dry-out. The thermal resistance was shifted down by approximately $0.25 \mathrm{~K} / \mathrm{W}$ or $20 \%$. Considering the $5 \%$ scatter in the three water tests, this was a significant improvement.

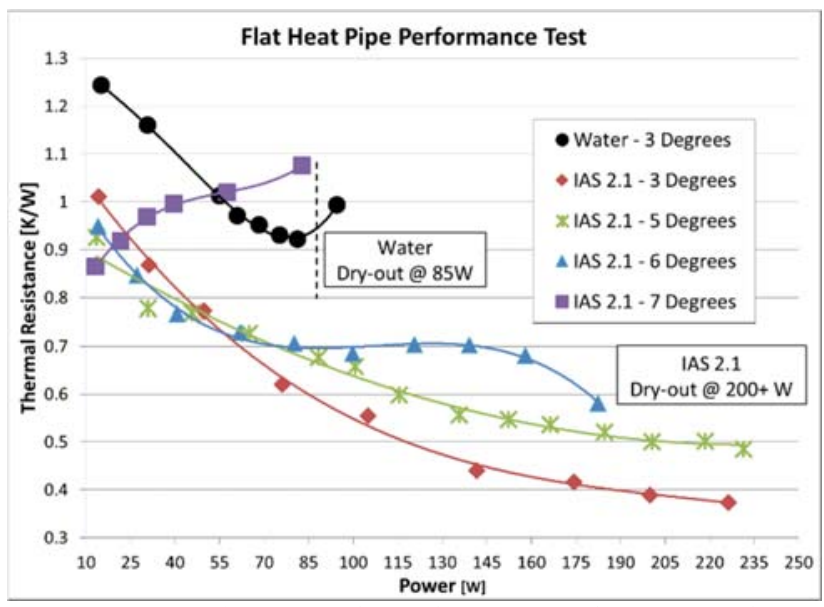

Figure 8: Performance dependency on inclination angle

At a three degree inclination and low power, the grooves were completely full of liquid regardless of the working fluid. Theoretically there should not have been any exposed coating, no additional wicking, and thus no additional evaporative surface area and decrease in thermal resistance. However, IAS deposits began to appear on the tops of the grooves as soon as the test was initiated. The early deposits were unexpected considering the solubility analysis done by Yao et al. [11] in which coating generation was predicted at much higher temperatures. Initial deposits could be a result of increases in local concentrations due to advection along the grooves which is discussed further in Section 5. Higher concentrations would decrease the temperature in which the solubility limits are reached. These deposits allowed liquid to be wicked out of the groove and evaporated. This phenomenon explained the decrease in resistance at low powers. A magnified image of the several grooves, Figure 9, shows the deposits after 15 minutes at a power of $15 \mathrm{~W}$. At this early stage of operation, the fluid is purple due to the permanganate ions that have yet to react with the copper surface.

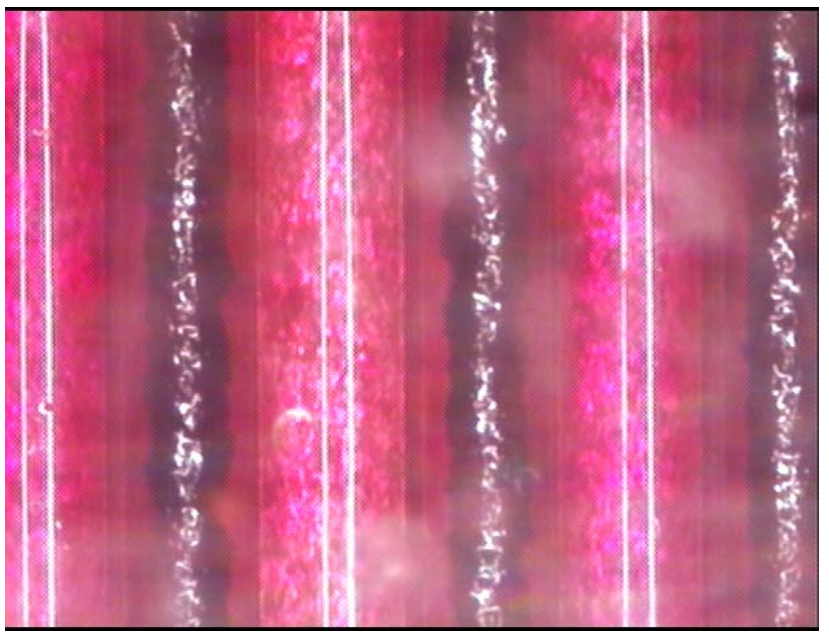

Figure 9: Heat pipe wick during operation

As the power increased to $80 \mathrm{~W}$ and beyond, no inflection point, or dry-out, was observed. Nucleation began to occur around $60 \mathrm{~W}$ but the resistance continued to drop and eventually reached values lower than $0.4 \mathrm{~K} / \mathrm{W}$. The test was finally stopped at $230 \mathrm{~W}$ due to limits in the apparatus. Temperatures in the heater block reached the melting temperature of the solder. The test was stopped to avoid fundamentally changing the system for further testing.

The results at a five degree inclination angle followed a similar trend. The thermal resistance exhibited a similar downward shift though the values were slightly higher at larger heat fluxes. Again, no dry-out was reached at this angle before the system temperature limits were reached.

At an inclination of six degrees, the grooves were not full initially. The bulk liquid in the groove receded about $1 \mathrm{~cm}$ down the plate though smaller menisci filled the corners of the grooves. The trend in thermal resistance differed slightly from the lower angles. Around $85 \mathrm{~W}$, the resistance curve flattens out at $0.7 \mathrm{~K} / \mathrm{W}$. This coincides with the dry-out point of water at an inclination of only three degrees. However, the thermal resistance is maintained and no inflection in resistance is observed. Even though the bulk liquid meniscus had receded slightly, the deposits continually wicked liquid up toward the evaporator. A picture of the grooves during operation is shown in Figure 10. The thick deposits on the top of the groove remained wet during the test as seen on the bottom right. Inside the groove, shown on the bottom left, the remaining liquid is spread out in a thin film over more coarse deposits. The different types and magnitudes of coating in each area of the grooves was a result of the strong advective flow throughout the test. The color of the fluid is also important to note. Its yellow color signifies that the permanganate has fully reacted out of solution. The yellow/orange color is due to the remaining chromate ions in solution. 


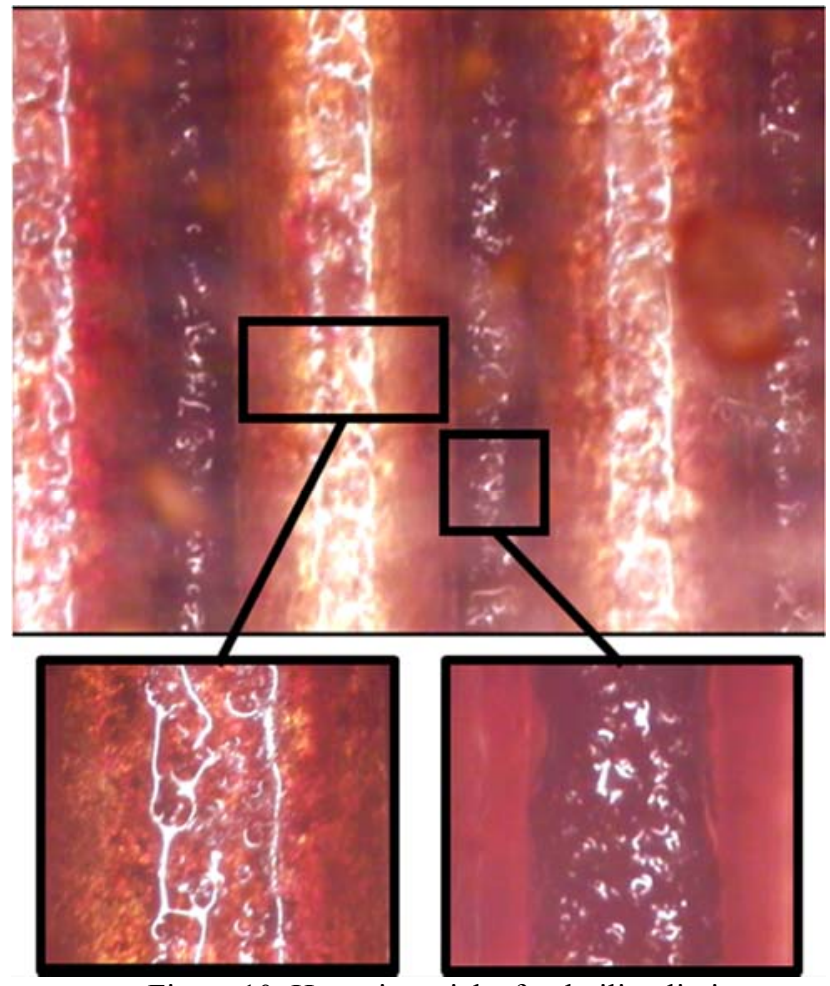

Figure 10: Heat pipe wick after boiling limit

At approximately $150 \mathrm{~W}$, the resistance begins to decrease until the test was stopped due to reaching the system temperature limits. The drop in resistance was possibly due to different evaporative heat transfer coefficients for the grooves and the coating. If evaporation was more efficient from the coating, due to the larger area covered by thin liquid film, the thermal resistance would decrease as the bulk liquid receded and more coating was exposed.

At an inclination angle of seven degrees, a limit in the previous performance trend of the designer fluid was reached. At this angle the resistance began to increase immediately as the heat flux was increased. The initial thermal resistance was still lower than for water. The wetting ability of the coating was enough to lower the initial thermal resistance but could not sustain a completely wetted surface.

At the end of each test, after the temperature limits of the set-up were reached, the power was switched off and the inclination angle was increased to keep the coating intact. The final dry coating is shown in Figure 11.

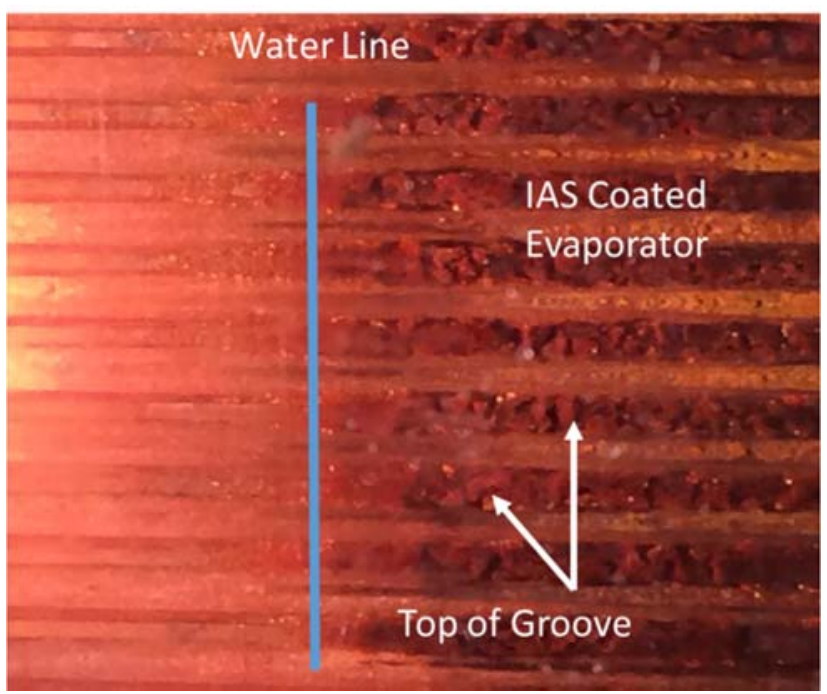

Figure 11: Surface augmentation resulting from designer working fluid

The plate was then imaged in a Hitachi S-4700 Scanning Electron Microscope (SEM). The top of the groove is shown in Figure 12 . The structures are highly irregular and porous and seem capable of wicking liquid. However, these structures may not be representative of the coating during operation. The deposits in Figure 9 and Figure 10 are not dry and are covered by a continuous thin film.

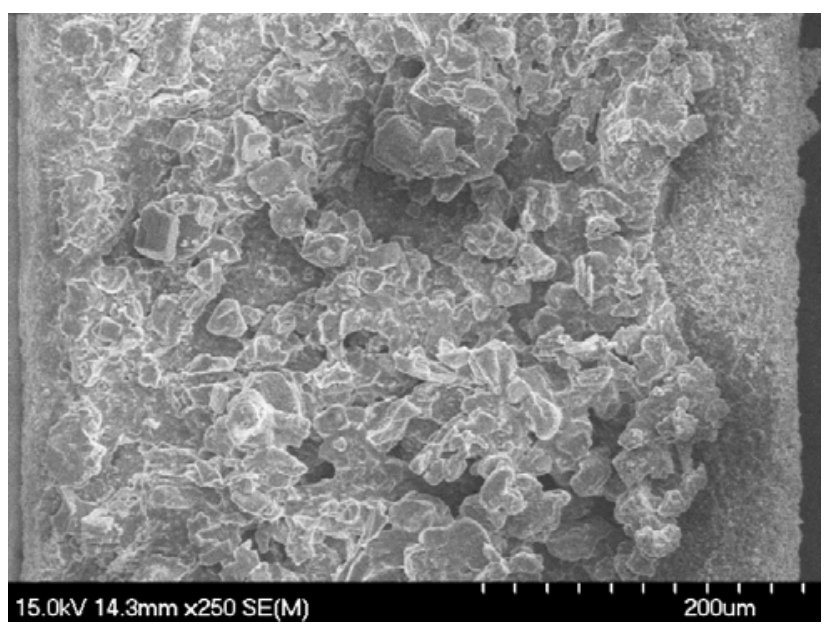

Figure 12: SEM of top of a single groove after the plate was completely dry

Without reaching the capillary limit in any of the tests with the designer fluid starting from fully primed grooves, a conclusion can't be made on the geometry or structure of the coating in a device that could reach this limit. The structures inside the groove helped spread the liquid but it's unclear whether the coating on the top of the groove aided in capillarity or if it simply increased the evaporative surface area.

\subsection{Effect of Designer Fluid Concentration}

Though the system limits prevented observation of dry-out for the IAS 2.1 designer fluid, IAS 2.2, containing twice the concentration of IAS 2.1, was tested. IAS 2.2 was tested at six and seven degrees as shown in Figure 13 and Figure 14. 


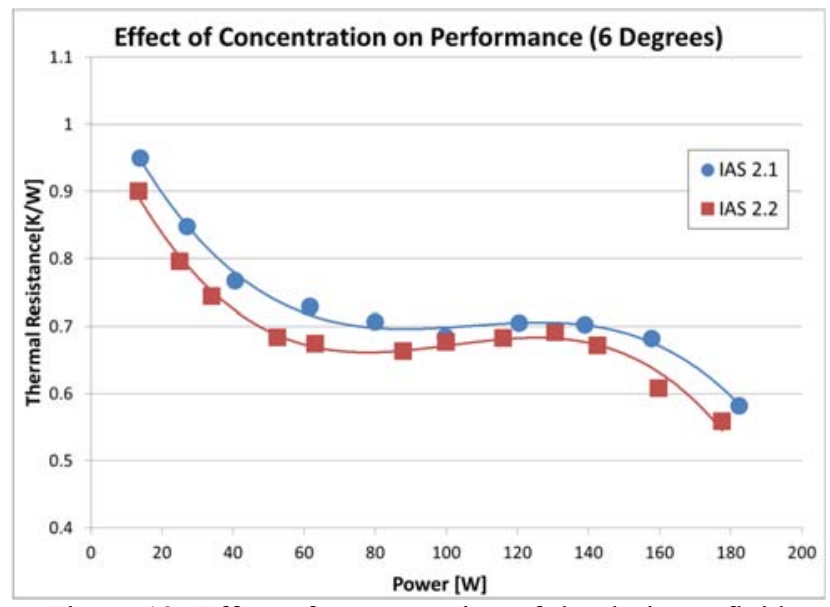

Figure 13: Effect of concentration of the designer fluid on thermal resistance at six degrees inclination

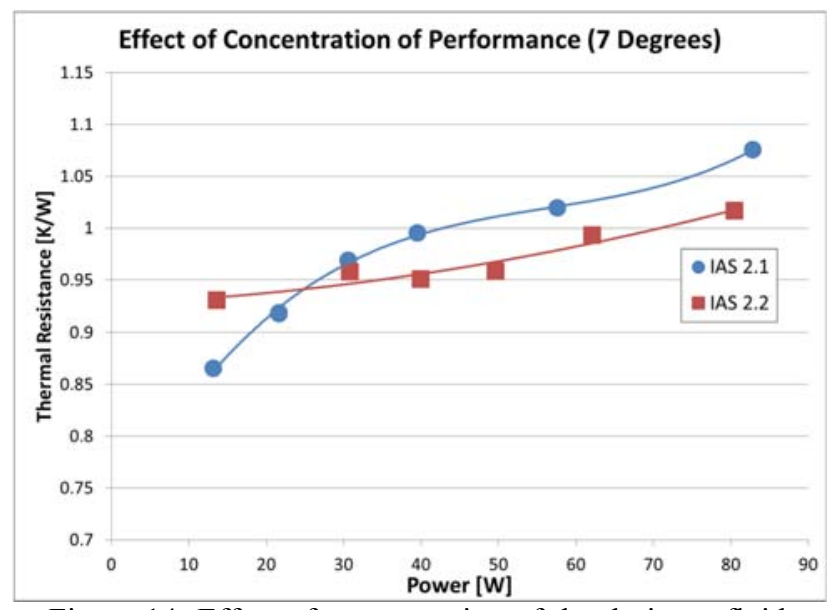

Figure 14: Effect of concentration of the designer fluid on thermal resistance at seven degrees inclination

The results at either inclination angle were very similar to that of IAS 2.1. The thermal resistances are lower at most heat fluxes but within 5\%. This difference is not significant enough to confirm any performance enhancement.

\subsection{Uncertainty Analysis}

Analysis of calibration and measurement uncertainty was performed based on the Root of Sum of Squares (RSS) method developed by Kline and Mclintock [22]. The NIST ITS-90 Type-T calibration curve was utilized for the thermocouple measurements [23]. The uncertainty in this calibration curve was $\pm 0.03{ }^{\circ} \mathrm{C}$. The NIST data was based on a $0{ }^{\circ} \mathrm{C}$ reference junction so the voltages read by the multimeter had to be adjusted based on the reference temperature of the thermocouple switch. The temperature of the thermocouple switch was measured using an Omega $10 \mathrm{k} \Omega$ thermistor and an Omega CN16DPT-220 temperature controller each with a \pm 0.2 ${ }^{\circ} \mathrm{C}$ uncertainty. The Agilent multimeter had a reported uncertainty of $\pm 0.0035 \%$ of the DC voltage readings. The Omega Type-T thermocouples had an inherent uncertainty of $0.5^{\circ} \mathrm{C}$. The uncertainty in the calibration curve, thermocouples, multimeter, and reference temperature measurement was combined using the RSS method to find the overall uncertainty in each temperature measurement. The total uncertainty of the temperature measurements was calculated to be $\pm 0.58{ }^{\circ} \mathrm{C}$.
Uncertainty in the input heat flux was calculated with the RSS method propagated through Fourier's Law shown below,

$$
\frac{\delta q_{\text {in }}}{q_{\text {in }}}=\left\{\left(\frac{\delta k}{k}\right)^{2}+\left(\frac{\delta A_{s}}{A_{s}}\right)^{2}+\left(\frac{\delta \Delta T_{s}}{\Delta T_{s}}\right)^{2}+\left(\frac{\delta x_{s}}{x_{s}}\right)^{2}\right\}^{1 / 2}
$$

The thermal conductivity of 110 copper alloy $\left(390 \mathrm{~W} / \mathrm{m}^{2}-\mathrm{K}\right)$ was assumed to have $\mathrm{a} \pm 2 \%$ uncertainty. The uncertainty in the heat stem dimensions were estimated from the resolution of the digital callipers used for the measurements. The uncertainty of the distance between stem thermocouples, $x_{s}$, and stem cross sectional area, $A_{s}$, was assumed to be $\pm 0.1 \mathrm{~mm}$ and $\pm 0.01 \mathrm{~mm}^{2}$ respectively. The uncertainty in the temperature difference was calculated to be $\pm 0.81{ }^{\circ} \mathrm{C}$. For the water tests, the maximum uncertainty in the input power was calculated to be $\pm 3.8 \mathrm{~W}$. At the first few input powers, $15-30 \mathrm{~W}$, this uncertainty was about $\pm 10-20 \%$ of the input power. At larger powers the percentage uncertainty decreased to $\pm 4 \%$. The uncertainty in the input power for the IAS tests reached $\pm 6.17 \mathrm{~W}$ due to the much larger values for input power. However, the percentage uncertainty was similar to water, $\pm 10-20 \%$ at low powers and $\pm 3 \%$ at higher powers.

The resistance uncertainty was calculated by combining the uncertainty in the input power and the temperature difference of the plate between thermocouple \#1 and the average of thermocouples \#9 and \#10.

$$
\frac{\delta R_{F H P}}{R_{F H P}}=\left\{\left(\frac{\delta \Delta T_{F H P}}{\Delta T_{F H P}}\right)^{2}+\left(\frac{\delta q_{\text {in }}}{q_{\text {in }}}\right)^{2}\right\}^{1 / 2}
$$

The maximum uncertainty was $\pm 0.26 \mathrm{~K} / \mathrm{W}$ at $15 \mathrm{~W}$, slightly over $26 \%$. The uncertainty decreased to $0.041 \mathrm{~K} / \mathrm{W}$ at larger input powers lowering the uncertainty to $\pm 4.5 \%$. For IAS, the resistance uncertainty was $\pm .22 \mathrm{~K} / \mathrm{W}(11 \%)$ at $15 \mathrm{~W}$ and below $\pm 0.03 \mathrm{~K} / \mathrm{W}(2.4 \%)$ at higher powers.

\section{DISCUSSION}

The decrease in thermal resistance and increase in operational limit are obvious advantages to the advanced working fluid. In addition, the IAS fluid enabled the flat heat pipe to maintain superior performance at larger angles of inclination. This feature is beneficial for applications that require the phase change devices to operate against gravity.

The sensitivity to inclination angle made it difficult to obtain optimal testing conditions for the aqueous solution. At low angles, the nucleation did not cause dry-out like it did with water as the working fluid. The angle was incrementally increased from three degrees to seven degrees in search for a better test case. The optimal case, where the grooves were full initially and receded throughout the test, was not found. In addition, the low heat flux nucleation further increased the uncertainty of finding this condition. However, the six degree case, which started in a receded state, demonstrated a mode of operation that occurs in a capillarity limited situation that does not exist with water. Though the bulk liquid in the groove was receded, the deposits on the top and interior of the groove remained wetted. From a heat transfer perspective, having the entire groove covered by a thin film is preferred over a filled groove due to a reduction in conductive thermal resistance through the liquid. So, even though the bulk meniscus was 
receded, the heat pipe performed as though it was not yet beyond the capillary limit.

The effect of concentration on performance must be addressed with regards to the magnitude of wick pore size. The coating thickness shown in Figure 11 is on the same order of magnitude as the already relatively large $1.5 \times 2 \mathrm{~mm}$ groove geometry. In addition, the deposits exist primarily on the top of the grooves. From these observations, the concentration, or amount of coating generating chemical mass, is in excess for the present surface area. The excess chemicals are simply deposited on top of the groove explaining why there was no additional performance increase with IAS 2.2.

The deposition on the top of the grooves was due to the strong advective forces in a heat pipe. The recirculation of liquid creates a constant flow toward the evaporator. The chemical constituents were concentrated in the evaporator, especially at the evaporating thin film in the groove meniscus. This effect is typically described as the "coffee-stain" effect , where advective forces dominate over diffusive forces causing particles or solutes to accumulate near the contact line [24]. This concentration caused the chromate salts to immediately reach the solubility limit.

In devices with small pore sizes, such as those seen in sintered wicks, the increases in capillarity must also be weighed with decreases in permeability as well as the possibility of clogging, as seen in the study done by Reilly and Catton [10]. For pore sizes on the order of a micron, deposits on the order of a micron will alter the permeability significantly. The grooved wick in this work had large pores and plenty of space on the surface between the grooves. The excess deposits had negligible effects on the large inherent permeability of the wick and no negative effect on performance.

\subsection{Future Work}

The grooved plate was chosen for simplicity and observation but does not allow the study of concentration limits. In future tests, the fluid concentration will be increased from zero to study the gradual performance increases. The nucleation and absence of capillary limit also created difficulty in fully analyzing the designer fluids. The grooves were simply too large to reach the capillary limit at reasonable temperatures and heat fluxes. Nucleation added uncertainty into how the designer fluid would perform in capillarity limited situation. The next experiments will incorporate a wick geometry that allows the capillary limit to be reached in order to fully understand how the designer fluids perform.

\section{CONCLUSION}

A type of chemically reacting advanced working fluid was experimentally studied in a flat heat pipe with a grooved wick. The working fluid demonstrated superior thermal performance and ability to extend the dry-out point compared to water. The performance increases was attributed to surface augmentation created by the working fluid. The surface coating increases the capillarity limit of the device by keeping the surface of the evaporator covered with liquid due wicking over the small pores in the deposits. The IAS fluids decreased the thermal resistance by approximately $20 \%$ and nearly tripled the capillary limit. The surface structures created by the working fluid also allowed the heat pipe to operate at higher inclination angles.
The deposition mechanisms of the fluid were observed and it was found that advective flow caused chemical deposits to form primarily on the tops of the grooves. The deposits on the interior of the groove, though less pronounced, allowed the surface of the grooves to stay wetted after the recession of the bulk liquid and maintain a low thermal resistance.

This study also served as a gauge for the relative amount of chemical constituents in the original fluid. The excessive deposits on the tops of the grooves suggest that a far lower concentration is necessary for the surface area of the grooves in the study. Overall, the fluid demonstrated excellent potential for improving the performance of phase change heat transfer devices.

\section{ACKNOWLEDGMENT}

This material is based upon work supported by the National Science Foundation under Grant No. CBET-1336896 in the Morrin-Gier-Martinelli Heat Transfer Memorial Laboratory at the University of California, Los Angeles.

\section{REFERENCES}

[1] Faghri, A., 1995, Heat pipe science and technology, Global Digital Press.

[2] Mochizuki, M., Nguyen, T., Mashiko, K., Saito, Y., Nguyen, T., and Wuttijumnong, V., 2011, "A Review of Heat Pipe Application Including New Opportunities," Frontiers in Heat Pipes (FHP), 2(1).

[3] Plawsky, J., Fedorov, A., Garimella, S., Ma, H., Maroo, S., Chen, L., and Nam, Y., 2014, "Nano-and Microstructures for Thin-Film Evaporation-A Review," Nanoscale and Microscale Thermophysical Engineering, 18(3), pp. 251-269.

[4] Sureshkumar, R., Mohideen, S. T., and Nethaji, N., 2013, "Heat transfer characteristics of nanofluids in heat pipes: A review," Renewable and Sustainable Energy Reviews, 20, pp. 397-410.

[5] Kiatsiriroat, T., Nuntaphan, A., and Tiansuwan, J., 2000, "Thermal performance enhancement of thermosyphon heat pipe with binary working fluids," Experimental Heat Transfer, 13(2), pp. 137-152.

[6] Zhang, N., 2001, "Innovative heat pipe systems using a new working fluid," International communications in heat and mass transfer, 28(8), pp. 1025-1033.

[7] Kim, H. D., and Kim, M. H., 2007, "Effect of nanoparticle deposition on capillary wicking that influences the critical heat flux in nanofluids," Applied Physics Letters, 91(1), p. 014104. [8] Han, Z., 2008, "Nanofluids with enhanced thermal transport properties."

[9] Catton, I., Tao, H. T., Reilly, S. W., Amouzegar, L., Yao, Q., Stubblebine, M. J., and Supowit, J., 2013, "Inorganic aqueous solution (ias) for phase-change heat transfer medium," Google Patents.

[10] Reilly, S. W., and Catton, I., 2011, "Utilization of advanced working fluids with biporous evaporators," Journal of thermal science and engineering applications, 3(2), p. 021006 .

[11] Yao, Q., Stubblebine, M., Reilly, S., Amouzegar, L., and Catton, I., "Using an Inorganic Aqueous Solution (IAS) in Copper and Aluminum Phase Change Heat Transfer Devices," Proc. ASME 2013 International Mechanical Engineering Congress and Exposition, American Society of Mechanical Engineers, pp. V08BT09A012-V008BT009A012. 
[12] Supowit, J., Yamada, K., and Catton, I., 2015, "Experimental Investigation of Designer Working Fluids in a Flat Heat Pipe," Proc. 30th IEEE SEMI-THERM.

[13] Supowit, J., Reilly, S., Amouzegar, L., and Catton, I., "A Novel Inorganic Aqueous Solution and its Effect on Liquid Spreading and Freeze/Thaw Processes," Proc. ASME 2013 Heat Transfer Summer Conference collocated with the ASME 2013 7th International Conference on Energy Sustainability and the ASME 2013 11th International Conference on Fuel Cell Science, Engineering and Technology, American Society of Mechanical Engineers, pp. V002T007A039V002T007A039.

[14] Bico, J., Thiele, U., and Quéré, D., 2002, "Wetting of textured surfaces," Colloids and Surfaces A: Physicochemical and Engineering Aspects, 206(1), pp. 41-46.

[15] Wayner, P., Kao, Y., and LaCroix, L., 1976, "The interline heat-transfer coefficient of an evaporating wetting film," International Journal of Heat and Mass Transfer, 19(5), pp. 487-492.

[16] Wong, S. C., and Chen, C. W., 2012, "Visualization and evaporator resistance measurement for a groove-wicked flatplate heat pipe," International Journal of Heat and Mass Transfer, 55(9-10), pp. 2229-2234.

[17] Stubblebine, M., and Catton, I., 2015, "Passivation and Performance of Inorganic Aqueous Solutions in a Grooved Aluminum Flat Heat Pipe," Journal of Heat Transfer, 137(5).

[18] Chi, S., 1976, "Heat pipe theory and practice," Washington, DC, Hemisphere Publishing Corp.; New York, McGraw-Hill Book Co., 1976. 256 p., 1.

[19] Lefèvre, F., Lips, S., Rullière, R., Conrardy, J.-B., Raynaud, M., and Bonjour, J., 2012, "Flat plate heat pipes: from observations to the modeling of the capillary structure," Frontiers in Heat Pipes (FHP), 3(1).

[20] Hopkins, R., Faghri, A., and Khrustalev, D., 1999, "Flat miniature heat pipes with micro capillary grooves," Journal of heat transfer, 121(1), pp. 102-109.

[21] Chen, S. W., Hsieh, J. C., Chou, C. T., Lin, H. H., Shen, S. C., and Tsai, M. J., 2007, "Experimental investigation and visualization on capillary and boiling limits of micro-grooves made by different processes," Sensor Actuat a-Phys, 139(1-2), pp. 78-87.

[22] Kline, S. J., and McClintock, F., 1953, "Describing uncertainties in single-sample experiments," Mechanical engineering, 75(1), pp. 3-8.

[23] Burns, G. W., Scroger, M., Strouse, G., Croarkin, M., and Guthrie, W., 1993, "Temperature-electromotive force reference functions and tables for the letter-designated thermocouple types based on the ITS-90," NIST, Monograph 175 , p. 630 .

[24] Deegan, R. D., Bakajin, O., Dupont, T. F., Huber, G., Nagel, S. R., and Witten, T. A., 1997, "Capillary flow as the cause of ring stains from dried liquid drops," Nature, 389(6653), pp. 827-829.

\section{NOMENCLATURE}

$\begin{array}{lll}\text { Symbol } & \text { Quantity } & \text { SI Unit } \\ A & \text { Surface area } & \mathrm{m}^{2} \\ F H P & \text { Flat heat pipe } & \\ I A S & \text { Inorganic aqueous solution } & \\ k & \text { Thermal conductivity } & \mathrm{W} / \mathrm{m}^{2}-\mathrm{K} \\ x & \text { Length } & \mathrm{m} \\ \Delta T & \text { Temperature difference } & \mathrm{K} \\ q & \text { Heat power } & \mathrm{W} \\ R & \text { Thermal resistance } & \mathrm{K} / \mathrm{W} \\ \text { Subscript } & \text { Quantity } & \\ & & \\ S & \text { Stem } & \end{array}$

